\title{
Gastric Cancer pT1b TNM Finding v7
}

National Cancer Institute

\section{Source}

National Cancer Institute. Gastric Cancer pT 1b TNM Finding v7. NCI Thesaurus. Code C89833.

Gastric cancer invading the submucosa. (from AJCC 7th Ed.) 